\title{
Ovarian Dermoid Cyst with Melanocytic
} Nevus

National Cancer Institute

\section{Source}

National Cancer Institute. Ovarian Dermoid Cyst with Melanocytic Nevus. NCI Thesaurus. Code C40002.

A secondary melanocytic nevus that has developed in an ovarian dermoid cyst. 